\title{
How can data from headwater catchments be used to improve runoff and nutrient predictions at larger scales?
}

\author{
E. Storr, R. Adams and A. Western \\ Department of Infrastructure Engineering, University of Melbourne, Parkville, VIC. \\ Email: rada@unimelb.edu.au
}

\begin{abstract}
Intuitively there should be a difference in the runoff and nutrient generation from catchment areas of varying sizes. The total runoff and constituent load can be modelled using one of the many hydrological models. However, how well a model performs can depend on the size of the catchment that it is applied to. In this study the modelling system Source Catchments is examined, to see if it can be improved when applied to different sized subcatchments to generate the total runoff and constituent concentrations. Within Source Catchments the AWBM model for predicting runoff on a daily timestep, is coupled with the EMC/DWC constituent generation model to predict sediment and nutrient concentrations in the study catchment.
\end{abstract}

The catchment used for this study is the Lang Lang Catchment (LLC) in West Gippsland about 100km southeast of Melbourne. The Lang Lang River runs into the Western Port Bay taking with it nutrients from the surrounding lands. The catchment area can be broken up into several sub-catchments. These were chosen due to the availability of existing data and the different geology of the headwater subcatchments. Monitoring of runoff, sediments and nutrients has taken place at several points since the early 1980s. Within the area there are two dominant types of land use, dryland agriculture (mostly dairy farming with some beef) and forestry. Each of these land uses have their event mean concentrations (EMC) and dry weather concentrations (DWC) initially assigned from previous studies and then re-calibrated using the nutrient data obtained from the Victorian Data Warehouse from 1982-1994. From this the runoff and total constituent load (in this case the total loading into the bay) are calculated through modelling. The model is validated using recent water quality data from 2000 to 2010 from three points (allowing the effect of differing landforms and geology on water quality to also be investigated).

Since 2009, monitoring has been taking place on a small farm in Poowong East, which lies within the southeastern headwaters of the LLC. The creeks on the property have three sub-catchments (the PECs) from where runoff and nutrient concentration data have been collected at scales from 1.2 to $4.4 \mathrm{~km}^{2}$. The land is almost entirely used for dryland dairy and beef farming with some small areas of woodland along riparian zones. This data is used to validate the LLC Source Catchments model again, at this scale. A comparison between results from the PECs and LLC indicates how well the model can work at the different catchment scales. Initially the EMC \& DWC parameters are the same for both simulations. It is known from existing monitoring data that there are lower nutrient concentrations (hence there would be lower EMC \& DWC values if these data were used to fit the model) in the LLC compared to the PECs. Given that the measured concentrations of nitrogen and phosphorous are greater from the PECs it is expected therefore that the model will underpredict nutrient concentrations there. The model can be recalibrated using the data from the PECs although this process should highlight some limitations of the EMC/DWC model approach, when nutrient concentrations (particularly EMCs) are variable over time and space due to local effects such as grazing and point sources of nutrients. Moreover, applying EMC \& DWC parameters fitted to the PECs, to the LLC may cause it to overpredict concentrations and loads discharging into Western Port Bay. Therefore, suggestions are made of methods to improve on the EMC/DWC constituent model used to estimate loads from the LLC. A model that defines functional units to take into account geology and landform, as well as land use could improve the accuracy of runoff and nutrient load predictions. The LLC model probably cannot account for the generation effects in a small headwater subcatchment through which the water moves quite rapidly. The model could be improved by dividing the river into reaches between additional water quality monitoring sites. The losses could be modelled using an in-stream (link-based) sink term. Additional monitoring data from the monitoring agency could also enable the model to be improved. If compliance with Victorian Government state Environmental Protection Policy (SEPP) standards is to be met throughout the catchment the monitoring agency needs to be able to predict water quality in all reaches, not just at the outlet into Western Port Bay.

Keywords: Hydrological modelling, Source Catchments, Lang Lang River, nutrients, sediments 


\section{INTRODUCTION}

Models perform differently depending on the size of the catchment area. Intuitively there should be a difference in the nutrient loadings generated from catchment areas of varying sizes due to attenuation and uptake of nutrients along river reaches. Also, model performance can often depend on the size of the catchment that it is applied to. Catchment simulation can assist catchment managers in monitoring water quality, in order for improvements to be made (Drewry et al., 2005). In this study the modelling system Source Catchments (EWater, 2010) has been examined, to see if the performance varies when it is applied to different sized catchments, to generate the total runoff and constituent (nutrients and sediments) concentration. In this study, within Source Catchments runoff is modelled using the Australian Water Balance Model (AWBM) (Boughton, 2004). Constituents were modelled using the event mean concentration/dry weather concentration (EMC/DWC) approach, which has been commonly used in Australia for estimating sediment and nutrient loads into rivers and estuaries (e.g. Argent, 2006; Argent et al., 2007; Adams et al., 2009).

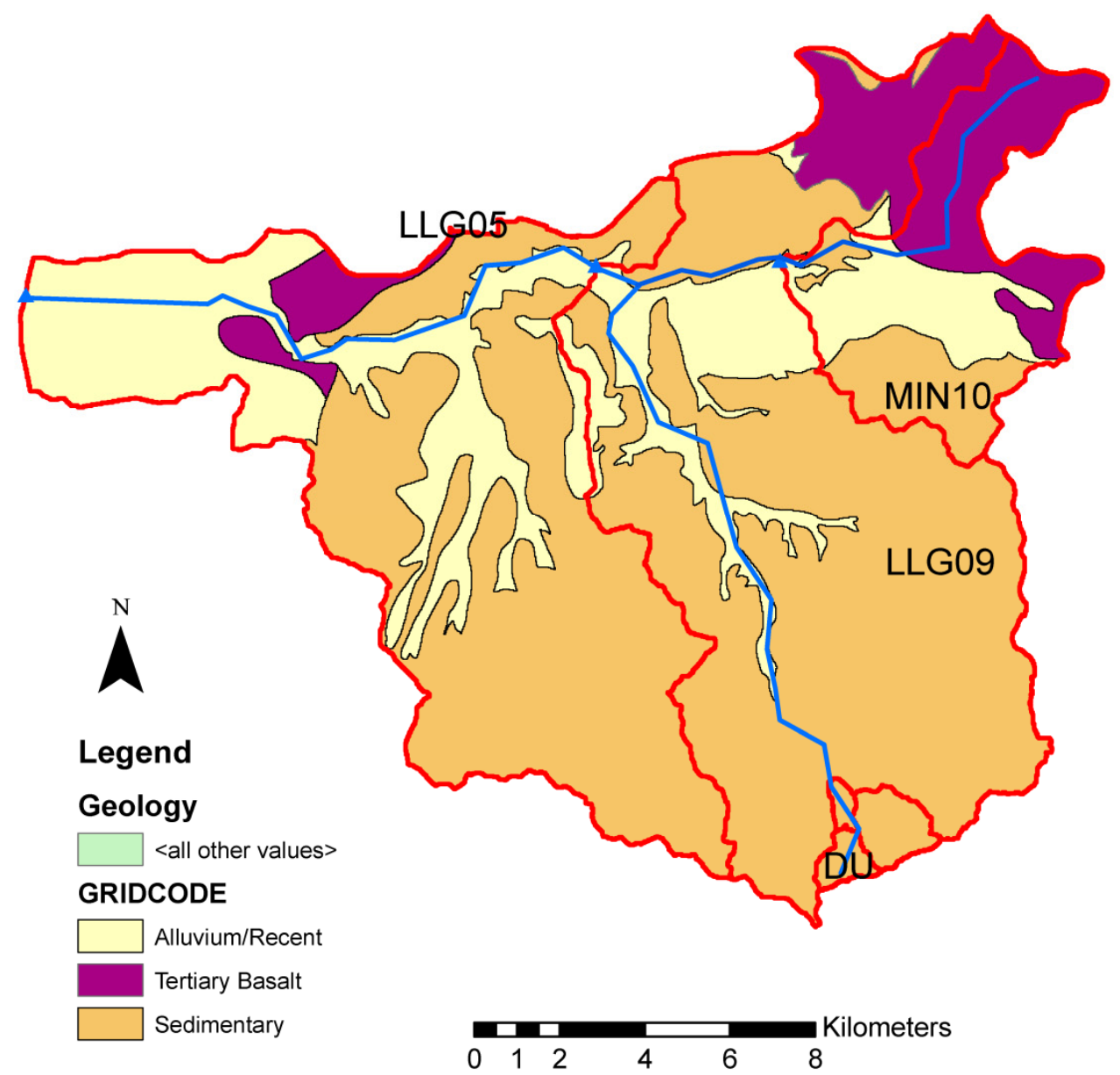

Figure 1: Map of the Lang Lang Catchment showing Melbourne Water monitoring sites (blue triangles), and PECs (DU)

This conceptual model assumes that runoff during events will have different concentrations of any constituent compared to dry weather conditions. This seems to be valid for nutrients such as phosphorus (P) where concentrations in different flow pathways (in this model runoff and baseflow) exhibit these large differences, in this case due to runoff transporting particulate forms of P (Dougherty et al., 2004). The comparison between results should indicate how well the model can work at different catchment scales.

\subsection{Study Area and Monitoring Data}

The catchment used for this study is the Lang Lang Catchment (LLC) in West Gippsland about $100 \mathrm{~km}$ southeast of Melbourne (Figure 1). The Lang Lang River drains an area of approximately $300 \mathrm{~km}^{2}$ and runs into the Western Port Bay delivering nutrients generated from the catchment. Monitoring of runoff, sediments and 
nutrients has taken place at several points since the early 1980s by the monitoring agency, Melbourne Water (MW) (Coleman \& Pettigrove, 2001) on a routine monthly basis. The catchment model is therefore constructed of several different sub-catchments based on the runoff and nutrient monitoring points so that model output can be compared with observed data. In this study three LLC subcatchments were used based on: (1) Minnieburn Ck (the northeast catchment area, MIN10); (2) Lang Lang River at Drouin-Poowong Road in Athlone (LLG09); (3) at Yannathan (or Hamiltons Bridge) (LLG05). Daily flow and nutrient data from 1982 to 1994 were also available from the Victorian Data Warehouse (DWH) site $228209^{1}$. This site is co-located with the MW site LLG05, and gauges an area of $277 \mathrm{~km}^{2}$. The Lang Lang catchment has been assessed as one of the largest contributors of sediment and nutrient loads into Western Port Bay (Coleman \& Pettigrove, 2001). Concentrations of total nitrogen (TN) and total phosphorus (TP) are regularly in excess of the Victorian Government SEPP water quality target standards for coastal catchments in eastern Victoria. Figure 2 shows the observed concentrations of TN, TP and total suspended solids (TSS) at the three DWH \& MW monitoring sites described above plus an additional MW site 7km downstream at the South Gippsland Highway bridge (LLG01).
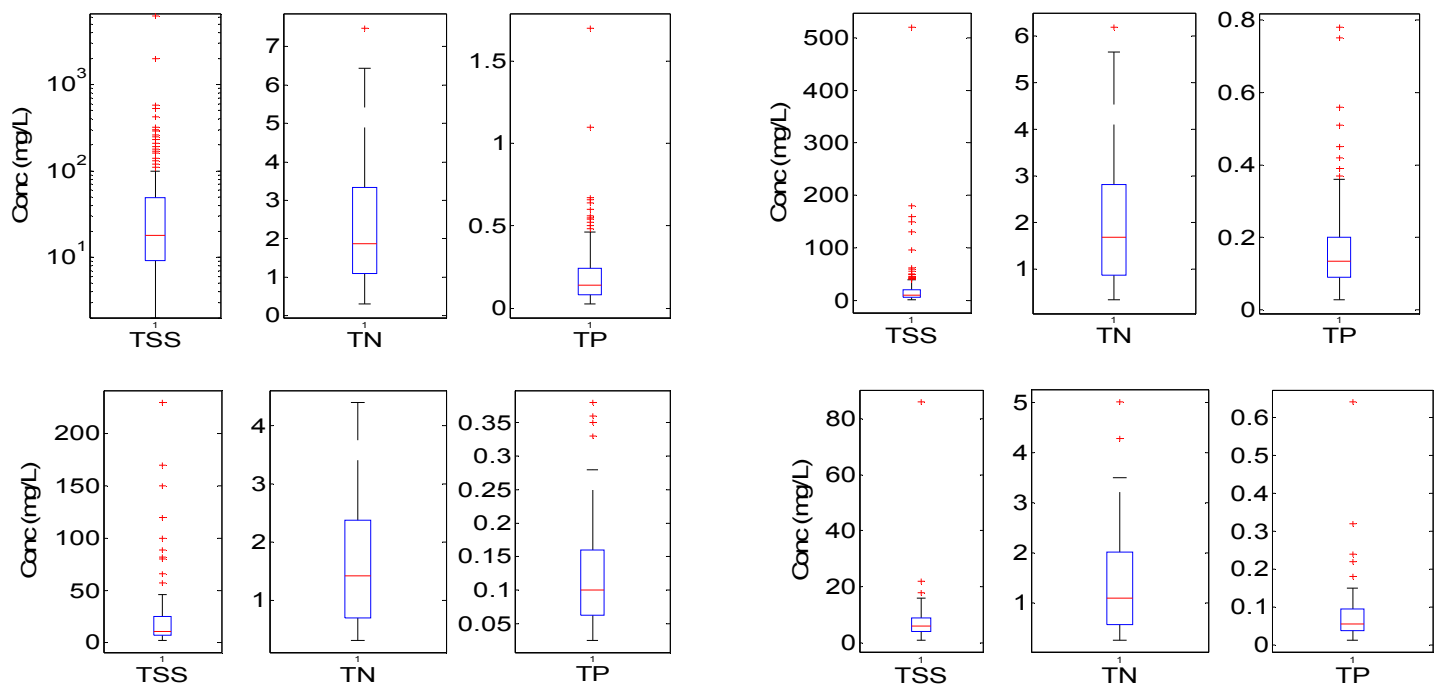

Figure 2 Observed Concentrations of TSS, TN and TP at Monitoring Sites (a-TL) LLG01, (b-TR) LLG05, (c-BL) LLG09, (d-BR) MIN10

Monitoring has been taking place on a small farm in Poowong East, which lies within the south-eastern headwaters of the LLC since 2009 by Melbourne and Monash Universities. The creeks on the property have three sub-catchments at scales from 1.2 to $4.4 \mathrm{~km}^{2}$. The land is almost entirely used for non- irrigated dairy and beef farming with some small areas of woodland along riparian zones. Water quality has been monitored from these since 2009, with runoff data measured at 10 minute intervals since April 2010, using V-notch weirs and a theoretical rating. 14 events were monitored for TP and TN in 2010 at the smallest of the thee subcatchments shown in Fig. 1 DU, using an ISCO ${ }^{\mathrm{TM}} 6712$ autosampler that was programmed to collect samples at 1 hour intervals after being triggered by rising stage at the onset of an event. From these data, flow-weighted means (FWMs) were calculated in order to normalise all the monitoring data onto a daily timestep. For events lasting more than one day the FWM concentration of TP and TN was assigned to the day of the event with the highest daily mean flow. Observed concentrations are shown in Figure 3 by the open markers.

When modelling the LLC the following constituents were simulated: TN,TP and TSS. The catchment area is also made up of three different types of geology. These comprise: sedimentary rock; Tertiary basalt and recent deposits (sand dunes, river terrace gravels, and alluvium deposited on the floodplain). Figure 1 shows the LLC with the subcatchment boundaries and simplified geology. The small area in the south east corner represents the three Poowong East headwater catchments (PECs). These consist of one type of geology; namely Cretaceous sedimentary rocks (mostly mudstones and sandstones) of the Otway Group (Geoscience Australia, 1997).

Land use in the catchment was available from the BRS mapping of Western Port and Port Phillip catchments (BRS, 2003) and covered approximately $89 \%$ of the LLC. Of this, $92 \%$ was agricultural (mostly dairy farming with some beef), with the remainder being a mix of low-density residential development and remnant woodland. Flows in the Lang Lang River were highly variable over the modelled period (1982-2010), with daily mean flows averaging 141.8 ML/day (or $187 \mathrm{~mm} /$ year). Rainfall and climatic data were obtained from the gridded

\footnotetext{
${ }^{1}$ (http://www.vicwaterdata.net/vicwaterdata/data warehouse content.aspx?option=4)
} 
daily BOM Australian Water Availability Product (AWAP) (http://bom.gov.au/jsp/awap) for the LLC model. Daily rainfall data from a MW gauge at Upper Lang Lang (ID586219) was used in the PEC model as the gauge is only $3 \mathrm{~km}$ away from the catchment boundary.

\section{MODELLING METHODOLOGY}

The parameters for the AWBM model were calibrated using the Rainfall Runoff Library (RRL) (Podger, 2004) at gauge 228209, for the period 1982-94. This effectively calibrated the model for the whole of the Lang Lang Catchment since this gauge lies close to the estuary draining into Western Port Bay. The 1994-2010 period was used for validating the model. Results indicated that the model predicted the observed daily runoff with a mass balance error (MBE) of $+2.9 \%$ (overprediction) and a Nash-Sutcliffe Efficiency (NSE) of 0.65 . Two functional units (FUs) were defined in Source Catchments, Agricultural (92\%) and Non-Agricultural (8\%). Each FU had its event mean concentration (EMC) and dry weather concentration (DWC) parameters assigned initially from Set 1; a previous modelling study (Argent, 2006), and then calibrated using the nutrient data obtained from the Victorian Data Warehouse from 1982-1994. The modelled and observed concentrations were compared with the mean and $90^{\text {th }}$ percentile values (to represent the dry weather and event conditions respectively). If the difference was greater than $10 \%$, the parameters were adjusted until this criterion was achieved if possible. Using this method the EMC \& DWC parameter values for each constituent, for the Agricultural FU, were recalibrated to create Set 2, since the Set 1 parameters underpredicted all three constituents at LLG05.

The Source Catchments constituent model was then validated by comparing the modelled concentrations against the 1994-2010 data from the three Melbourne Water sampling points. More recent data from site LLG05 were not available so site LLG01, the lowest sampling point at the South Gippsland Highway bridge, was used instead (the sites are only $7 \mathrm{~km}$ apart with no significant tributary inputs so it was assumed that the water quality at both sites was similar). Modelled concentrations were the same at all 3 points since the land use and climate data were not varied in the initial Source Catchments model setup, and exceeded the observed concentrations at Minnieburn Creek (MIN10) for all three constituents. At the sites on the Lang Lang mainstem (LLG09 and LLG01), the error in the modelled mean and $90^{\text {th }}$ percentile concentrations was more than $25 \%$, with the model underpredicting all 3 constituents at LLG01.

In order to improve the model, the LLC geology was taken into account since this varied across the catchment (Fig. 1). This was done by splitting the Agriculture FU into three FUs using three different types of geology (Alluvium, sedimentary rock and Tertiary basalt - as shown in Fig. 1) and recalibrating the EMC \& DWC parameters for each new FU. The resulting parameter set was Set 3, shown in Table 1. The percentage of nonagricultural land uses was too small to justify a similar approach for this FU, so it retained the original Western Port EMC \& DWC parameters (Set 1).

Next, a Source Catchments model of the headwater catchments (PECs) was set up. AWBM was recalibrated on a single $1.2 \mathrm{~km}^{2}$ subcatchment (DU) comprising several dairy and beef farms, using RRL. Runoff data were available for a six-month period only in 2010 before the weir was destroyed by a flood; however the results indicated that a NSE of 0.5 and MBE of $-0.9 \%$ (underprediction) could be obtained by calibrating AWBM on this dataset (observed mean runoff $2.2 \mathrm{ML} / \mathrm{d}$, total $410.6 \mathrm{~mm}$ ). Water quality data were available for the same period, except for TSS which was only measured in a few grab and event samples in 2009. The Source Catchments PEC model uses only one set of EMC/DWC parameters (for the FU AgSed which covered 100\% of the subcatchment) for each constituent, from Set 3 . The model was then recalibrated with the DU water quality dataset for the period $16 / 4 / 2010$ to $10 / 2 / 2011$, to obtain parameter set 4 for TP and TN. 
Table 1 EMC and DWC values for the Lang Lang Catchment and the Farm Catchment (DU)

\begin{tabular}{|c|c|c|c|c|c|}
\hline $\begin{array}{l}\text { Land use } \\
\text { (FU) }\end{array}$ & Set & Geology & Constituent & $\begin{array}{l}\text { DWC } \\
(\mathrm{mg} / \mathrm{L})\end{array}$ & $\begin{array}{l}\text { EMC } \\
(\mathrm{mg} / \mathrm{L})\end{array}$ \\
\hline \multicolumn{6}{|c|}{ Lang Lang Catchment (LLC) } \\
\hline \multirow[t]{3}{*}{ Agricultural } & 2 & None & TP & 0.09 & 0.27 \\
\hline & & & $\mathrm{TN}$ & 1.16 & 4.06 \\
\hline & & & TSS & 2.8 & 99 \\
\hline \multirow[t]{3}{*}{ Non Agricultural } & All & None & $\mathrm{TP}$ & 0.05 & 0.1 \\
\hline & & & $\mathrm{TN}$ & 0.5 & 1.5 \\
\hline & & & TSS & 6 & 40 \\
\hline \multirow[t]{9}{*}{ Agricultural } & 3 & Alluvial \& Recent & $\mathrm{TP}$ & 0.14 & 0.34 \\
\hline & & (AgAll) & $\mathrm{TN}$ & 2 & 5.1 \\
\hline & & & TSS & 8 & 60 \\
\hline & & Sedimentary Rock & $\mathrm{TP}$ & 0.14 & 0.35 \\
\hline & & (AgSed) & $\mathrm{TN}$ & 2 & 5.1 \\
\hline & & & TSS & 8 & 60 \\
\hline & & Tertiary & TP & 0.02 & 0.12 \\
\hline & & Basalt & $\mathrm{TN}$ & 0.48 & 2 \\
\hline & & $(\mathrm{AgTB})$ & TSS & 4 & 14 \\
\hline \multicolumn{6}{|c|}{ Farm Catchment (DU) } \\
\hline \multirow[t]{3}{*}{ Agricultural } & 4 & Sedimentary Rock & $\mathrm{TP}$ & 0.058 & 1.05 \\
\hline & & (AgSed) & $\mathrm{TN}$ & 1.2 & 5.5 \\
\hline & & & TSS & Insufficient & Data \\
\hline
\end{tabular}

\section{RESULTS}

Table 2 shows the predicted error for each constituent modelled using Sets 2, 3 and 4. A positive error indicates that the modelled concentration was over-predicted by Source Catchments. The errors using a previous parameter set on a different site or time period (e.g. Set 1 on LLG01) were (obviously) much greater than calibrated sets, so are not shown for brevity. It should be clear from the EMC\&DWC parameter values in Table 1 that each set has quite different values except for: EMC TP for AgSed (Set 3) and Ag (Set 2), EMC TN for AgSed (Set 3 and Set 4), DWC TN AgSed (Set 4) and Ag (Set 2).

Table 2 Water Quality Model Performance

\begin{tabular}{|c|c|c|c|c|c|c|c|c|c|}
\hline \multirow{2}{*}{$\begin{array}{l}\text { Site } \\
\text { Code }\end{array}$} & \multirow{2}{*}{$\begin{array}{l}\text { Area } \\
\left(\mathrm{km}^{2}\right)\end{array}$} & \multirow[t]{2}{*}{ Set } & \multirow{2}{*}{$\begin{array}{l}\text { Time } \\
\text { Period }\end{array}$} & \multicolumn{2}{|c|}{ TP } & \multicolumn{2}{|c|}{ TN } & \multicolumn{2}{|c|}{ TSS } \\
\hline & & & & $\begin{array}{l}\text { \% Error } \\
\text { (mean) }\end{array}$ & $\begin{array}{l}\% \text { Error } \\
\left(90^{\text {th }} \text { ile }\right)\end{array}$ & $\begin{array}{l}\text { \% Error } \\
\text { (mean) }\end{array}$ & $\begin{array}{l}\% \text { Error } \\
\left(90^{\text {th }} \text { ile }\right)\end{array}$ & $\begin{array}{l}\text { \% Error } \\
\text { (mean) }\end{array}$ & $\begin{array}{l}\% \text { Error } \\
\left(90^{\text {th }} \text { ile }\right)\end{array}$ \\
\hline LLG05 & 277 & 2 & $28 / 2 / 80-31 / 10 / 94$ & 10.6 & -0.9 & 12.2 & 0.4 & 9.9 & -4.3 \\
\hline LLG01 & 300 & 3 & $1 / 4 / 92-9 / 4 / 10$ & -15.8 & -41.4 & 6.9 & -9.7 & -78.7 & -73.3 \\
\hline LLG09 & 115.2 & 3 & $1 / 4 / 92-9 / 4 / 10$ & -2.9 & -9.8 & 19.2 & 7.9 & -9.1 & -1.9 \\
\hline MIN10 & 34.6 & 3 & $22 / 6 / 07-9 / 4 / 10$ & 33.1 & 15.4 & 31.5 & 20.8 & 55.0 & 116.2 \\
\hline DU & 1.2 & 4 & $30 / 4 / 10-9 / 2 / 11$ & 7.7 & -8.8 & -7.6 & 0.9 & $\mathrm{~N} / \mathrm{A}$ & N/A \\
\hline
\end{tabular}

\section{DISCUSSION}

Focussing first on the largest scale catchment (Lang Lang LLG05), the runoff model (AWBM) tended to overpredict runoff during the dryer period from 1994-2010, however this was not felt to be the main problem 
affecting the model performance at predicting concentrations. In the EMC/DWC model, the concentrations are sensitive to the proportion of event flow (runoff), which takes the (in this case higher) EMC concentration, and the split between runoff and baseflow is controlled by the BFI parameter in AWBM. Runoff model parameters (not shown) indicated that much smaller storage capacities (C1-C3) were required to simulate the flashy response of the DU headwater catchment (runoff coefficient 0.47 ).

It was not possible to satisfactorily derive a parameter set for all three of the agricultural FUs split according to geology (i.e. Set 3). The results in Table 2 show that the mean concentrations at site MIN10 were predicted to be far too high, so that the approach of calibrating EMC \& DWC parameters for each constituent with three geological types (Set 4) was not successful. It was possible to calibrate the EMC \& DWC values for all three FUs to reproduce TP concentrations at site LLG09, and TN concentrations at site LLG01, within +- 10\% (Table 2). It may be that the dryland agriculture in the Minnieburn subcatchment is less intense than in the other parts of the catchment, and that geology is not suitable as an attribute to subdivide spatially this land use. It is more likely that the short period of the water quality data from MIN10 (2007 to 2010) and the proliferation of samples collected at very low flows was insufficient to capture the full range of water quality variability and underestimated the mean and $90^{\text {th }}$ percentile concentrations used as "observed" data. It was not possible to fit the TSS data from site LLG01, possibly due to an unknown point source of sediment near the catchment outlet leading to higher observed TSS concentrations, or due to bed and bank erosion from the channelized Lang Lang River (Coleman \& Pettigrove, 2001).

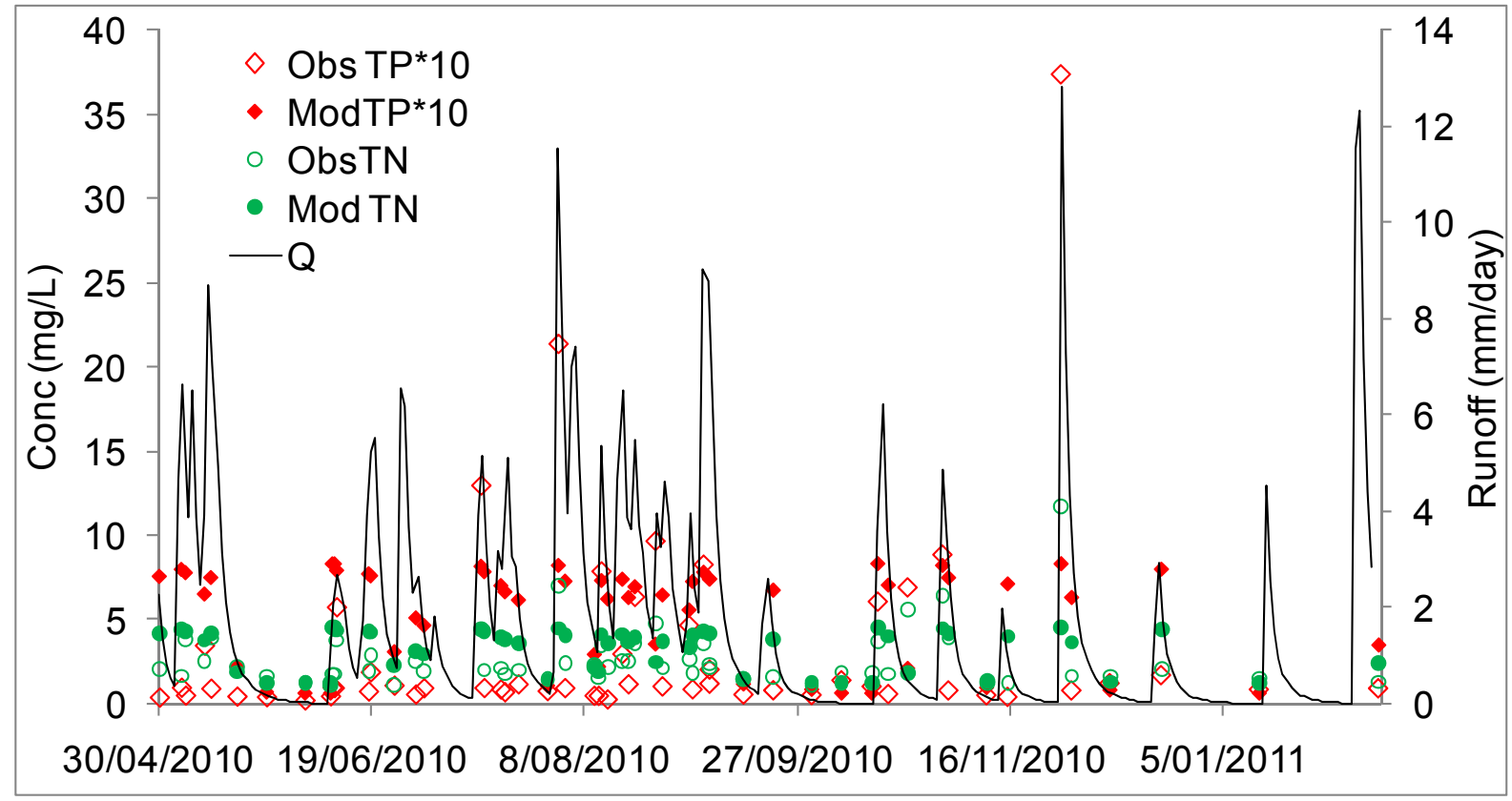

Figure 3. Modelled Runoff (Q) and Concentrations of TP and TN at site DU

Applying the Source Catchments model to the PEC subcatchment DU $\left(1.2 \mathrm{~km}^{2}\right)$ produced acceptable results in terms of reproducing the daily runoff and mean concentrations of TN and TP. However, Source Catchments was unable to reproduce the variability in measured (FWM) concentrations during storm events, due to its nutrient model assuming a single EMC concentration for all storms (solid markers in Figure 3 indicate modelled concentrations). Event FWM concentrations for TP varied from 0.1 to $3.7 \mathrm{mg} / \mathrm{L}$ and for TN between 1.7 and $11.7 \mathrm{mg} / \mathrm{L}$ (open markers). The monitoring program at Poowong East was focussed on storm events, whereas the MW monitoring was on a routine monthly basis. Therefore the dataset collected at DU is likely to be biased towards higher concentrations of TN and TP (as these were positively correlated with flow). This limitation of the EMC/DWC approach has been highlighted in other studies (Drewry et al., 2005). Although there was no 2010 data to fit the model, grab and event samples collected for TSS analysis in 2009 indicated a range of observed concentrations between 12.9 and $1332 \mathrm{mg} / \mathrm{L}(\mu=396 \mathrm{mg} / \mathrm{L}, \mathrm{n}=5)$, with a mean in excess of the TSS EMC parameter (Set 3: $99 \mathrm{mg} / \mathrm{L}$ ) for AgSed by an order of magnitude.

Compared to the monitoring site closest downstream (LLG09) nutrient concentrations in 2010 at DU were higher for TP (DU: $\mu=0.32 \mathrm{mg} / \mathrm{L}, \mathrm{n}=39$ vs. LLG09: $\mu=0.223 \mathrm{mg} / \mathrm{L}, \mathrm{n}=9$ ). A different pattern was seen in TN, at LLG09 $(\mu=2.51 \mathrm{mg} / \mathrm{L}, \mathrm{n}=9)$ compared to DU $(\mu=2.0 \mathrm{mg} / \mathrm{L}, \mathrm{n}=39)$. The DU-derived parameters (Set 4 in Table 2) were higher for both TP and TN than the LLC-derived AgSed parameters, for EMC (Set 3). As mentioned above this could be due to the focus of the PEC monitoring being on storm events, where it was observed that the TP concentrations tended to increase more than TN concentrations relative to their respective 
baseflow values (Fig. 3), probably due to particulate P sources mobilized during storms (Dougherty et al., 2004). However, most samples collected from the Lang Lang River under all flow conditions still recorded values in excess of the SEPP standards for coastal catchments in Victoria.

\section{CONCLUSIONS AND RECOMMENDATIONS}

Firstly, a Source Catchments model of the circa $300 \mathrm{~km}^{2}$ Lang Lang catchment is likely to be able to predict annual mean concentrations of nutrients transported into Western Port Bay, if calibrated on water quality data from the lowest monitoring site (LLG01) closest to the estuary, i.e. calibration needs to be site-specific. Predicting TSS concentrations may be more problematic using this approach possibly due to unknown sources of sediment. Runoff predictions at the outlet gauge (228209) were within reasonable error bounds so loads can also be estimated providing uncertainty bounds are defined. Secondly, an enhanced Source Catchments model with both improved representation of nutrient and sediment generation mechanisms and spatial representation of different subcatchments, would be needed to simulate: (i) the concentration of nutrients and sediments during runoff events, probably at all scales; (ii) the spatio-temporal variability of concentrations at different scales in the catchment (of the order of 1 to $100 \mathrm{~km}^{2}$ ) caused by either localized variations in agricultural intensity or other factors.

Lastly, small headwater catchments (e.g. Poowong East) with homogeneous land use and geology can provide additional information on runoff and water quality variability, but obtaining this requires extensive monitoring of storm events coupled with routine baseline monitoring and runoff measurements. Concentrations of nutrients (TP and TN) measured from the $1.2 \mathrm{~km}^{2} \mathrm{DU}$ site indicated more temporal variability than the existing Source Catchments EMC/DWC model could simulate, especially with TP, concentrations of which increased more relative to baseflow in runoff events than TN. Moving to $40-300 \mathrm{~km}^{2}$ scale, the routine monitoring data from the three current MW sampling sites did not permit geology to be used to divide up the FU representing agricultural areas of the catchment. This may reflect the mixture of geological types in each of the subcatchments. In any case monitoring at these sites should continue since water quality has been shown to be highly variable across the Lang Lang catchment.

\section{ACKNOWLEDGEMENTS}

Melbourne Water, for supplying their hydrological and water quality monitoring data for the catchment.

The dataset from the PECs was collected under ARC DP0987738. The input of project staff and students at Melbourne and Monash Universities is acknowledged in collecting and analysing this.

\section{REFERENCES}

Adams, R., Western, A.W., Law, S. and Andersen, S. (2009). The Development of an Integrated Modelling Framework for Assessing the Impacts of Land Use Change on Corner Inlet. In Proceedings: 18th World IMACS / MODSIM Congress, Cairns, Australia.

Argent R. (2006). PortsE2: A Decision Support System for Water Quality Improvement in Port Phillip and Western Port, CEAH Report. University of Melbourne, Parkville, VIC.

Argent R.M.., Pexton H.B., McAlister A.B. (2007). The PortsE2 Decision Support System - An Application of E2 In Proceedings: 17th World IMACS / MODSIM Congress, Christchurch, NZ.

Boughton, W. (2004). The Australian water balance model, Environmental Modelling \& Software, 19, 943-956. BRS. (2003). Land Use in South-West Victoria, Port Phillip Region (Zone 55). Available online at http://adl.brs.gov.au/anrdl/metadata_files/pa_lupprr9abll06811a00.xml

Coleman, R. and Pettigrove, V. (2001) Waterway assessment in the Western Port Catchment: The health of the Lang Lang River, Waterways Group: Melbourne Water Corporation.

Dougherty, W.J., Fleming, N.K., Cox, J.W., and Chittleborough, D.J. (2004). Phosphorus Transfer in Surface Runoff from Intensive Pasture Systems at Various Scales: A Review. J. Environ. Qual., 33, 1973-1988.

Drewry, J.J., Newham, L.T.H., Greene, R.S.B., Jakeman, A.J., and Croke, B.F.W. (2005). A review of nitrogen and phosphorus export to waterways: context for catchment modeling. Marine and Freshwater Research, 57, 757-774.

Geoscience Australia. (1997). 1:250,000 Warragul map sheet SJ5510. Available online at: www.geoscience.gov.au.

eWater Cooperative Research Centre. (2010). Source Catchments Scientific Reference Guide, eWater Cooperative Research Centre, Canberra.

Podger, G. (2004). Rainfall Runoff Library Users Guide, eWater (formerly CRC-CH) Cooperative Research Centre, Canberra 110pp. 